\title{
Leprosy reactions: the effect of gender and household contacts
}

\author{
Giuseppe Mastrangelo', Joaquim da Silva Neto ${ }^{3}$, Gilberto Valentim da Silva ${ }^{3}$, Luca Scoizzato', \\ Emanuela Fadda', Monique Dallapicola ${ }^{4}$, Ana Luiza Folleto ${ }^{4}$, Luca Cegolon ${ }^{1,2} /+$
}

\author{
'Department of Environmental Medicine and Public Health, Padua University, Padua, Italy \\ ${ }^{2}$ School of Public Health, Imperial College London, London, UK ${ }^{3}$ Fondazione Frà Roggero Caccia Dominioni, Venice, Italy \\ ${ }^{4}$ Departamento de Medicina Social, Universidade Federal do Espírito Santo, Vitória, ES, Brasil
}

Various host-related factors have been reported as relevant risk factors for leprosy reactions. To support a new hypothesis that an antigenic load in local tissues that is sufficient to trigger the immune response may come from an external supply of Mycobacterium leprae organisms, the prevalence of reactional leprosy was assessed against the number of household contacts. The number of contacts was ascertained at diagnosis in leprosy patients coming from an endemic area of Brazil. The prevalence of reactions (patients with reactions/total patients) was fitted by binomial regression and the risk difference $(R D)$ was estimated with a semi-robust estimation of variance as a measure of effect. Five regression models were fitted. Model 1 included only the main exposure variable "number of household contacts"; model 2 included all four explanatory variables ("contacts", "fertile age", "number of skin lesions" and "bacillary index") that were found to be associated with the outcome upon univariate analysis; models 3-5 contained various combinations of three predictors. Male and female patients were analyzed separately. In females, household contacts were a significant predictor for leprosy reactions in model 1 [crude $R D=0.06 ; 95 \%$ confidence interval $(C I)=0.01 ; 0.12]$ and model $5(R D=0.05 ; C I=0.02 ; 0.09)$, which included contacts, bacillary index and skin lesions as predictors. Other models were unsatisfactory because the joint presence of fertile age and bacillary index was a likely source of multicollinearity. No significant results were obtained for males. The likely interpretation of our findings might suggest that in female patients, leprosy reactions may be triggered by an external spreading of M. leprae by healthy carrier family members. The small number of observations is an obvious limitation of our study which requires larger confirmatory studies.

Key words: leprosy - household contacts - reactions - healthy carriers - chemoprophylaxis

Although leprosy is a chronic infectious disease, it may be considered an immunologic disease too (Lupi et al. 2006, Naafs 2006). In fact, a noticeable proportion of leprosy patients suffer from immunologic hypersensitivity reactions at any given time in the disease process, including before, during and after treatment. These adverse immunological reactions are now the most significant issue in the management of leprosy.

There are two primary types of leprosy reaction: (i) type 1 reaction: also called reversal reaction occurs only in patients with borderline disease and is associated with oedema, increased erythema, potential ulceration of existing skin lesions and nerve damage, which is the major concern and (ii) type 2 reaction: also called erythema nodosum leprosum, is a systemic inflammatory response which may manifest in fever, arthralgias, myalgias, anorexia, erythematous sparse tender nodules on the extensor surfaces of the extremities. Conjunctivitis, neuritis, keratitis, iritis, synovitis, nephritis, hepatosplenomegaly, orchitis and lymphadenopathy may also occur.

Financial support: Padua University

+ Corresponding author: 1.cegolon@gmail.com

Received 28 June 2010

Accepted 12 November 2010
Although several new drugs have been studied and found to be of some use, corticosteroids continue to be the mainstay treatment in the management of leprosy reactions. Unfortunately, the chronic administration of corticosteroids induces either minor (moon face, severe fungal skin infections, severe acne and gastric pain needing antacid) or major side effects (psychosis, peptic ulcer, glaucoma, cataracts, diabetes, hypertension and steroid dependency) resulting in permanent damage.

Various host-related factors have been reported as risk factors for leprosy reactions, such as female gender, pregnancy and breastfeeding, suffering from lepromatous leprosy, presence of a positive bacterial index, undergoing multi-drug therapy for leprosy, other medications, vaccinations, infections, injury and physical and mental stress (review in Mastrangelo et al. 2008). It has been reported that these factors are presumed to cause the multiplication of dormant viable Mycobacterium leprae (which are known to persist for many years in Schwann cells or in fibrous tissue without producing any ill effects) and the release of microbacterial antigens in the local tissues (Britton \& Lockwood 2004).

In endemic areas, it was found that: $M$. leprae survives outside of the human body, healthy individuals harbour M. leprae bacilli in the nasal cavity and microorganisms can be subsequently released into the environment and there is widespread subclinical transmission of $M$. leprae with transient infection of the nose resulting in the development of a mucosal immune response (review in Mastrangelo et al. 2008). 
This disparate clinical, epidemiologic and microbiologic evidence led to the hypothesis that an antigenic load in local tissues that is sufficient to trigger the immune response may result from an external supply of M. leprae organisms (Mastrangelo et al. 2008). In order to establish supporting evidence for this hypothesis, the prevalence of leprosy reactions among patients with $\mathrm{L}$ or B leprosy (Madrid classification) in an endemic area of Northeast Brazil were assessed against the number of household contacts and other explanatory variables that could influence the occurrence of reactions. These variables were studied separately for males and females.

\section{PATIENTS, MATERIALS AND METHODS}

Patients came from an endemic area (the town of Picos, state of Piauí, Northeast Brazil), where a nongovernmental organization supports the activity against leprosy in cooperation with the governmental health organization and local agents (Mastrangelo et al. 2009).

Among the patients treated for leprosy from 19982005 , only those diagnosed with L and B leprosy (Madrid classification) were selected. The medical histories of these patients were examined in August 2009 to select the cases of leprosy reactions. This extended time of observation allowed us to also study cases of late onset leprosy reactions. Reactional leprosy was diagnosed if a patient had inflammatory skin lesions and/or acute neuritis. The date of onset and resolution, the type of reaction and therapy were recorded for each episode of hypersensitivity. The following information was collected at the diagnosis of leprosy in all patients: gender, age [coded in 2 classes: 1545 years (fertile age) and all other ages], clinical diagnosis of leprosy (B or L leprosy, according to Madrid classification), year of diagnosis (before 2000, 2000 and after), number of household contacts (categories: 0, 1, 2, 3, 4 and more), contact type (loose or close if the patient lived with a partner), number of skin lesions ( $<6,6$ or more), number of body areas involved $(<3,3$ or more), bacillary index ( $<$ 3,3 or more), bacilloscopy (negative or positive), treatment schedule $(<12,12,13-23,24$ months).

Ethics - Enrolled patients were the same as those examined in a previous study (Mastrangelo et al. 2009). No ethical approval was required as a clearance was provided by Picos Local Health Authority. The records were handled according to the national rules on confidentiality.

Statistical analysis - Male and female patients were analyzed separately. The prevalence of reactional leprosy was estimated dividing the number of new cases of reactions by the total number of patients in each category of the extracted variables. Using Microsoft Excel, data were plotted on a graph ( $\mathrm{x}$-axis = number of household contacts; $\mathrm{y}$-axis $=$ prevalence of reactional leprosy). These data were fitted by a simple linear regression, with a straight-line expressing the trend.

The Chi-square $\left(\chi^{2}\right)$ test was computed in a series of two-by-two tables with a binary response $(1=$ reactional leprosy; $0=$ otherwise) and a dichotomous variable expressing a risk factor $(1=$ present; $0=$ absent $)$. When such variables were broken down into different classes, the Cochrane-Armitage test for linear trends was applied with the statistical package StatXact (Mehta \& Patel 1999).
Using STATA 10 (Stata Corporation, College Station, Texas, USA), the prevalence was fitted on generalized linear models for the binomial family, estimating risk difference (RD) with a semi-robust estimation[SE(RD)] of variance as a measure of effect. Five regression models were fitted. Model 1 included only the main exposure variable "number of household contacts"; model 2 included all four explanatory variables ("contacts", "fertile age", "number of skin lesions", "bacillary index") that were found to be associated with an increasing prevalence of leprosy reactions; models 3-5 contained various combinations of three predictors. Male and female patients were analyzed separately. A complete case analysis approach was adopted.

\section{RESULTS}

Table I shows the main characteristics of the patients. The mean age and the average number of contacts were fairly similar in both genders, whereas the percentage of leprosy reactions was slightly higher in male patients. Figure shows the scatter plot of the prevalence according to the number of contacts for men and women. In women, the prevalence increases with increasing number of contacts, whereas in men the trend was steady or declining.

\section{TABLE I}

Mean and standard deviation (SD) of age and number of dwelling contacts, number and percentage of leprosy reactions in female and male leprosy patients

\begin{tabular}{lccccc}
\hline & \multicolumn{2}{c}{$\begin{array}{c}\text { Age } \\
\text { (years) }\end{array}$} & $\begin{array}{c}\text { Number of } \\
\text { contacts }\end{array}$ & $\begin{array}{c}\text { Leprosy } \\
\text { reactions }\end{array}$ \\
\cline { 2 - 6 } Gender & Mean & SD & Mean & SD & $\mathrm{n}(\%)$ \\
\hline Females $(\mathrm{n}=102)$ & 48.87 & 17.39 & 3.53 & 2.48 & $29(28)$ \\
Males $(\mathrm{n}=222)$ & 47.25 & 18.09 & 3.74 & 2.41 & $83(37)$ \\
\hline
\end{tabular}

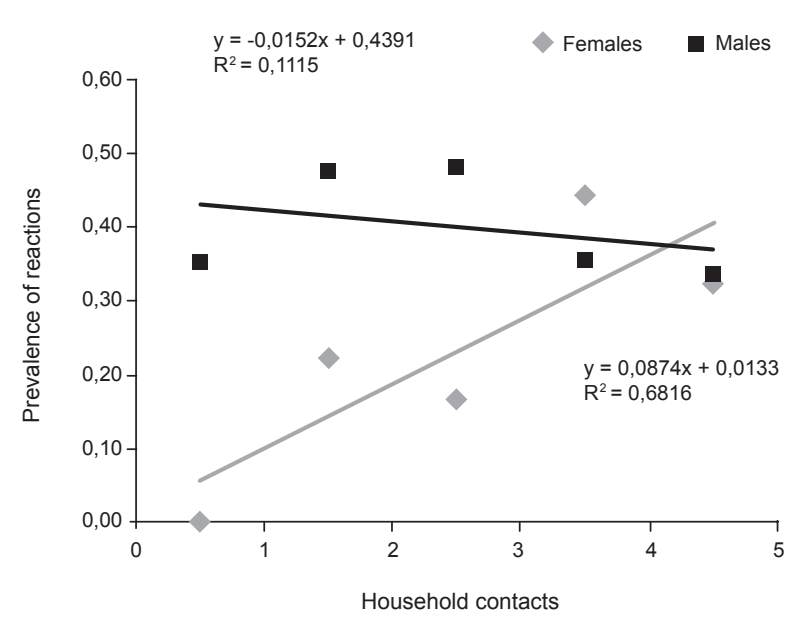

Scatter plot and linear relationship between the prevalence of developing leprosy reactions by increasing number of household contacts, separately for males and females. 
Table II shows that there is a substantial number of missing values, especially for skin lesions, body areas involved and bacillary index, variables that the clinical papers sometimes describe without providing numbers. Table II also shows the distribution of the cases (absolute number as well as percentage) in each stratum of independent variables. In men, the $\chi^{2}$ analysis did not indicate any significant results. In women, the percentage of leprosy reactions was significantly higher for those of fertile age $\left(\chi^{2} \mathrm{p}\right.$ value $\left.<0.01\right)$, with six or more skin lesions $\left(\chi^{2} \mathrm{p}\right.$ value $\left.=0.01\right)$ and with a bacillary index $\geq$ $3\left(\chi^{2} \mathrm{p}\right.$ values $\left.=0.01\right)$. An increasing trend of borderline significance ( $\mathrm{p}$ for trend $=0.07$ ) was observed with an increasing number of households contacts.

Table III displays the results of a multivariate binomial regression analysis in women: RD with $\mathrm{SE}(\mathrm{RD})$, z-test, $p$ value; $95 \%$ confidence interval $(95 \% \mathrm{CI})$ al- ways referring to number of household contacts only. Household contacts was a significant predictor for leprosy reactions in model 1 (crude $\mathrm{RD}=0.06 ; 95 \%$ $\mathrm{CI}=0.01-0.12)$. The adjusted RD (0.0533) provided by model 5 was lower than the corresponding crude estimate (0.0644). In model 5, SE(RD) was also smaller. Therefore, the RD estimate was more precise and statistically more significant (0.002). In model 4 , the adjusted RD was lower than the crude estimate, but the adjusted SE(RD) was larger. No estimate could be obtained in models 2 and 3 in which the algorithm for the deviance computation did not achieve convergence after 100,000 iterations. Both models were characterized by the joint presence of bacillary index and fertile age as predictors. In men, none of the above variables, including household contacts, were significant predictors (data not shown).

TABLE II

Number (n) and percentage (\%) of subjects with leprosy reactions (number of missing values) and Chi-square $\left(\chi^{2}\right) \mathrm{p}$ values in relation to the number of household contacts and variables that may influence the occurrence of reactions separately for males $(\mathrm{M})$ and females $(\mathrm{F})$

\begin{tabular}{|c|c|c|c|c|c|c|c|c|}
\hline \multirow[b]{2}{*}{ Variables } & \multirow[b]{2}{*}{ Classes $^{a}$} & \multirow[b]{2}{*}{ Missing } & \multicolumn{3}{|c|}{ M } & \multicolumn{3}{|c|}{$\mathrm{F}$} \\
\hline & & & $\mathrm{n}$ & $\%$ & $\begin{array}{c}\mathrm{p} \text { value } \\
\chi^{2}\end{array}$ & $\mathrm{n}$ & $\%$ & $\begin{array}{c}\mathrm{p} \text { value } \\
\chi^{2}\end{array}$ \\
\hline \multirow[t]{5}{*}{ Number of household contacts } & 0 & M: 6 & 6 & 0.35 & 0.27 & 0 & 0.00 & 0.07 \\
\hline & 1 & $\mathrm{~F}: 2$ & 10 & 0.48 & & 4 & 0.24 & \\
\hline & 2 & & 14 & 0.48 & & 2 & 0.17 & \\
\hline & 3 & & 15 & 0.36 & & 8 & 0.47 & \\
\hline & $4+$ & & 36 & 0.34 & & 15 & 0.33 & \\
\hline \multirow[t]{2}{*}{ Fertility age (years) } & Other & M: 1 & 60 & 0.44 & 0.30 & 11 & 0.17 & $<0.01$ \\
\hline & $15-45$ & & 31 & 0.37 & & 18 & 0.47 & \\
\hline \multirow[t]{2}{*}{ Number of skin lesions } & $<6$ & M: 31 & 28 & 0.37 & 0.64 & 5 & 0.14 & 0.01 \\
\hline & $6+$ & F: 17 & 46 & 0.41 & & 19 & 0.40 & \\
\hline \multirow[t]{2}{*}{ Number of body areas involved } & $<3$ & M: 27 & 22 & 0.42 & 0.74 & 3 & 0.14 & 0.13 \\
\hline & $3+$ & F: 14 & 54 & 0.39 & & 21 & 0.32 & \\
\hline \multirow[t]{2}{*}{ Diagnosis $^{b}$} & B & & 34 & 0.35 & 0.47 & 14 & 0.26 & 0.33 \\
\hline & $\mathrm{L}$ & & 49 & 0.40 & & 14 & 0.39 & \\
\hline \multirow[t]{2}{*}{ Bacillary index } & $<3$ & M: 11 & 51 & 0.35 & 0.14 & 17 & 0.23 & 0.01 \\
\hline & $3+$ & F: 5 & 28 & 0.46 & & 11 & 0.50 & \\
\hline \multirow[t]{2}{*}{ Bacilloscopy } & Negative & M: 11 & 5 & 0.45 & 0.61 & 1 & 0.20 & 0.50 \\
\hline & Positive & F: 5 & 74 & 0.38 & & 27 & 0.30 & \\
\hline \multirow[t]{2}{*}{ Contact type } & Loose & M: 6 & 15 & 0.31 & 0.16 & 11 & 0.27 & 0.79 \\
\hline & Close & F: 3 & 68 & 0.42 & & 17 & 0.30 & \\
\hline \multirow[t]{2}{*}{ Year of diagnosis } & $<2000$ & M: 3 & 47 & 0.44 & 0.14 & 14 & 0.30 & 0.62 \\
\hline & $2000+$ & F: 2 & 36 & 0.34 & & 14 & 0.26 & \\
\hline \multirow[t]{4}{*}{ Months of treatment } & $<12$ & M: 1 & 6 & 0.38 & 0.61 & 1 & 0.11 & 0.32 \\
\hline & 12 & F: 1 & 23 & 0.38 & & 7 & 0.23 & \\
\hline & $13-23$ & & 10 & 0.29 & & 6 & 0.43 & \\
\hline & 24 & & 44 & 0.42 & & 14 & 0.32 & \\
\hline
\end{tabular}

$a$ : see body text for specifications; $b$ : L and B leprosy (Madrid classification). 
TABLE III

Binomial regression analysis

\begin{tabular}{|c|c|c|c|c|c|c|}
\hline Models $^{a}$ & $\begin{array}{l}\text { Variables included } \\
\text { in the models }\end{array}$ & RD & $\mathrm{SE}(\mathrm{RD})$ & Z test & $\mathrm{p}$ value & $95 \% \mathrm{CI}$ \\
\hline 1 & Contacts & 0.0644 & 0.0298 & 2.16 & 0.031 & $0.0059 ; 0.1229$ \\
\hline 2 & Contacts, BI, F_age, skin_L & - & - & - & - & - \\
\hline 3 & Contacts, BI, F_age & - & - & - & - & - \\
\hline 4 & Contacts, F_age, skin_L & 0.0517 & 0.0312 & 1.65 & 0.098 & $-0.0095 ; 0.1129$ \\
\hline 5 & Contacts, BI, skin L & 0.0533 & 0.0170 & 3.13 & 0.002 & $0.0199 ; 0.0866$ \\
\hline
\end{tabular}

$a$ : models fitted for risk of leprosy reactions (outcome) [simple model including the main exposure variable only (1), saturated model with four predictors (2), models with various combinations of three predictors (3, 4 and 5)]; $\mathrm{BI}$ : bacillary index $(0=\mathrm{BI}<3$; $1=\mathrm{BI} \geq 3)$; contacts: number of household contacts; F_age: fertile age $(0=<15$ or $>45$ years; $1=15-45$ years $)$; skin_L: number of skin lesions $(0=<6 ; 1=\geq 6)$. -: impossible to estimate (convergence not achieved after 100,000 iterations). Risk difference (RD) (always referred to the variable "number of household contacts" only) with semi-robust estimation of variance [SE(RD)] and confidence interval (CI).

\section{DISCUSSION}

According to Checkoway et al. (2004), the differences between the crude and adjusted estimates could reflect the presence of confounding factors (adjusted RD values lower than the crude estimates) or multicollinearity [adjusted SE(RD) larger than the crude estimates]. Therefore, the results of model 4 could be attributed to both confounding effect and multicollinearity. The factor likely to be responsible for collinearity appears to be fertile age, which is included in model 4 as well as models 2 and 3 in which it was impossible to determine the corresponding results.

The main limitation of this study is the small sample size, particularly among females. It is reasonable to assume that a bigger sample size could minimize the multicollinearity issue (Checkoway et al. 2004).

Another important limitation of this retrospective analysis of clinical records is the lack of information regarding pregnancy status and breastfeeding, which are known risk factors for leprosy reactions (review in Mastrangelo et al. 2008). Fertile age has been employed in the present study as a proxy of pregnancy and breastfeeding status and this variable appeared to be involved in the multicollinearity rather than in the cofounding issue. This result might be explained by the fact that family size tends to be larger in middle age than in younger/older ages. Unfortunately, information on other possible relevant risk factors for leprosy reactions, such as vaccinations and infections status, was not available. Nevertheless, as most of the subjects suffering from leprosy reactions were treated with oral corticosteroids, it is reasonable to exclude co-existing acute infections in these of patients.

In this study, the presence of and a high number of household contacts was associated with an increasing prevalence of reactional leprosy only in women. Presuming that in the areas surveyed, women, unlike men, experience higher levels of social segregation at home with the family than men, the likely interpretation of our findings might suggest that in female patients leprosy reactions can be triggered by an external supply of $M$. leprae spread by a healthy carrier family member.

Clearly, the findings must be confirmed by other studies carried out in areas with similar social backgrounds and epidemiological burden of disease. To the best of our knowledge, there is no other similar data in the literature for comparison.

In 2000, a meta-analysis of published studies on chemoprophylaxis of leprosy found five trials (Dharmendra 1965, Noordeen 1969, 1977, Noordeen \& Neelan 1976, Neelan et al. 1986) which randomized individuals and a sixth which used the cluster method by randomizing villages (Wardekar 1967). The evidence showed that chemoprophylaxis against leprosy is an effective way to reduce the incidence of leprosy in household contacts (Smith \& Smith 2000). A more recent publication dealt with a single centre, double blind, cluster randomized, placebo-controlled trial carried out in two districts of northwest Bangladesh, which enrolled 28,092 close contacts of 1,037 patients with newly diagnosed leprosy. A total of 21,711 contacts fulfilled the study requirements, 18,869 of which were followed up at four years. A single dose of rifampicin or placebo was given to close contacts in two months after the index patient began treatment. A total of 91 of 9,452 contacts in the placebo group and 59 of 9,417 in the rifampicin group developed leprosy. There was a $57 \%$ overall reduction in the incidence of leprosy when using a single dose of rifampicin in the first two years (Moet et al. 2008). Another similar trial is proposed, comprising a randomized, controlled trial of chemoprophylaxis, using a single $10 \mathrm{mg} / \mathrm{kg}$ dose of rifampicin or a placebo among the household contacts of newly detected leprosy patients in nine projects in India. Based upon an assumption of a $50 \%$ protective efficacy of chemoprophylaxis, an annual incidence of two per 1,000 contacts, a desired power of the study of $90 \%$ and a $95 \%$ level of significance, 15,000 household contacts will be allocated randomly by household to each arm of 
the study and followed for five years. All people living in the same household as an index case and sharing the same kitchen will be considered as household contacts. To be certain that transmission of the organisms from the index case cannot occur once the prophylaxis has been administered, rifampicin will be given two months after diagnosis of the index case (Vijayakumaran et al. 2000).

The results of such future studies (or where possible, the results of previous studies) should be analyzed to examine whether leprosy reactions are reduced in patients whose household contacts belonged to the intervention group as opposed to the control group.

Finally, these results should be confirmed by following up the household contacts of leprosy patients. Serial nasal swabs should be collected from all subjects and kept at $-80^{\circ} \mathrm{C}$ and the proportion of healthy carriers among relatives of leprosy patients with or without reactional episodes should be compared.

\section{ACKNOWLEDGEMENTS}

To Daisy Alice Dunger, for her advice in the drafting of the manuscript, to Dr Patricia Albuquerque Martins Rodriguez (Municipal coordinator of Hanseniase, Picos, Piauí), who gave the permission to examine the archive of the leprosy service in Picos, and to His Excellency Frà Roggero Caccia Dominioni and Adeládio de Araújo Rocha, for their help in the field research.

\section{REFERENCES}

Britton WJ, Lockwood DN 2004. Leprosy. Lancet 363: 1209-1219.

Checkoway H, Pearce N, Kriebel D 2004. Research methods in occupational epidemiology, 2nd ed., Oxford University Press, New York, 286-288.

Dharmendra 1965. Prophylactic value of DDS against leprosy: an interim report. Lepr India 37: 1-20.

Lupi O, Madkan V, Tyring SK 2006. Tropical dermatology: bacterial tropical diseases. J Am Acad Dermatol 54: 559-578.
Mastrangelo G, Marcer G, Cegolon L, Buja A, Fadda E, Scoizzato L, Pavanello S 2008. How to prevent immunological reactions in leprosy patients and interrupt transmission of Mycobacterium leprae to healthy subjects: two hypotheses. Med Hypotheses 71: 551-563.

Mastrangelo G, Scoizzato L, Fadda E, Silva GV, Santos L de J, Cegolon L 2009. Epidemiological pattern of leprosy in an endemic area of North-East Brazil, 1996-2005: the supporting role of a Non-governmental Organization. Rev Soc Bras Med Trop 42: 629-632.

Mehta C, Patel N 1999. StatXact for Windows. Cytel Software Corporation, Cambridge.

Moet FJ, Pahan D, Oskam L, Richardus JH, COLEP Study Group 2008. Effectiveness of single dose rifampicin in preventing leprosy in close contacts of patients with newly diagnosed leprosy: cluster randomised controlled trial. BMJ 336: 761-764.

Naafs B 2006. Treatment of leprosy: science or politics? Trop Med Int Health 11: 268-278.

Neelan PN, Sirumban P, Sivaprasad N 1986. Limited duration acedapsone prophylaxis in leprosy. Indian J Lepr 58: 251-256.

Noordeen SK 1969. Chemoprophylaxis in leprosy. Lepr India 41: 247-254.

Noordeen SK 1977. Long term effects of chemoprophylaxis among contacts of lepromatous cases. Results of $81 / 2$ years follow-up. Lepr India 49: 504-509.

Noordeen SK, Neelan PN 1976. Chemoprophylaxis among contacts of non-lepromatous leprosy. Lepr India 48 (Suppl. 4): 635-642.

Smith CM, Smith WC 2000. Chemoprophylaxis is effective in the prevention of leprosy in endemic countries: a systematic review and meta-analysis. MILEP2 Study Group. Mucosal immunology of leprosy. J Infect 41: 137-142.

Vijayakumaran P, Krishnamurthy P, Rao P, Declerq E 2000. Chemoprophylaxis against leprosy: expectations and methodology of a trial. Lepr Rev 71 (Suppl.): S37-40.

Wardekar RV 1967. DDS Prophylaxis against leprosy. Lepr India 39: 155-159. 